\title{
Chesapeake Bay acidification buffered by spatially-separated calcium carbonate mineral formation and dissolution
}

\author{
WEI-JUN CAI ${ }^{1}$, JIANZHONG SU ${ }^{1}$, CHAOYING NI ${ }^{2}$, JEREMY \\ TESTA $^{3}, \mathrm{MING} \mathrm{LI}^{4}$ \\ ${ }^{1}$ School of Marine Science and Policy, University of \\ Delaware, College of Earth, Ocean, and Environment, \\ 111 Robinson Hall, Newark, DE 19716, USA \\ ${ }^{2}$ Materials Science and Engineering, University of Delaware, \\ Newark, DE 19716, USA \\ ${ }^{3}$ Chesapeake Biological Laboratory, University of Maryland \\ Center for Environmental Science, Solomons, MD 20688, \\ USA
}

${ }^{4}$ Horn Point Laboratory, University of Maryland Center for Environmental Science, Cambridge, MD 21613, USA

Uptake of anthropogenic carbon dioxide $\left(\mathrm{CO}_{2}\right)$ from the atmosphere has acidified the ocean and threatened the health of marine organisms and their ecosystems. In coastal waters, acidification is often enhanced by $\mathrm{CO}_{2}$ and acids produced during strong biological respiration. However, less is known about buffering processes that counter coastal acidification in eutrophic and seasonally hypoxic and anoxic water bodies, like the Chesapeake Bay. Here we use carbonate chemistry, mineralogical analyses and geochemical modeling to demonstrate the occurrence of a bay-wide $\mathrm{pH}$ buffering mechanism resulting from spatially-separated calcium carbonate mineral formation and dissolution. In summer, high rates of photosynthesis by dense submerged aquatic vegetation (SAV) at the head of the bay and in shallow, nearshore areas generate high $\mathrm{pH}$ (as high 10.1), elevated carbonate mineral saturation state, and net alkalinity uptake, leading to $\mathrm{CaCO}_{3}$ precipitation. Calcium carbonate particles produced under these conditions and biogenic $\mathrm{CaCO}_{3}$ are subsequently transported downstream or laterally into high $\mathrm{CO}_{2}$, low $\mathrm{pH}$ and carbonate mineral undersaturated corrosive subsurface deep waters, where their dissolution buffers $\mathrm{pH}$ decreases caused by aerobic respiration and anthropogenic $\mathrm{CO}_{2}$. Because this $\mathrm{pH}$ buffer mechanism would be strengthened by further nutrient load reductions and associated SAV recovery, our findings suggest that the reduction of nutrient inputs into coastal waters will not only reduce eutrophication and hypoxia, but also alleviate the severity of coastal ocean acidification. 